\title{
THE CONVERGENCE OF EMERGING INFORMATION AND COMMUNICATION TECHNOLOGIES: IMPLICATIONS FOR BUSINESS
}

\author{
RV Weeks (I B M)
}

A central tenet of network based technologies is their ability to eliminate geographical, distance and time constraints that have traditionally manifest themselves as boundaries encapsulating and protecting local business institutions from the more harsh realities of global competitive forces. The convergence of information and communication technologies in the Internet is not only of technological relevance, but also holds substantial implications for business in removing traditional boundaries and barriers to business operations.

Key words: digital divide, globalisation, information and communication technologies, technologically empowered, technologically disadvantaged

The Governor of the South African Reserve Bank, Mr TT Mboweni, in addressing the Black Management Forum Conference on 13 October 2000, brought home the true consequences of the reality of convergence of emerging information and communication technologies in stating that:

\begin{abstract}
"Financial markets around the world are being integrated into a single global market and, whether we like it or not, emerging and developing countries are being drawn into this process. The growing economic interdependence of countries worldwide can be seen in the greater volume and variety of cross-border transactions and in the faster and more widespread diffusion of technology ... Another consequence of globalisation, is increased competition. Financial liberalisation, the removal of controls and the breakdown of international barriers, make it possible for new entrants to participate in markets which were previously closed to them" (Mboweni 2000)
\end{abstract}

This statement gives meaning to the fact that South Africa is no longer an island unto itself, but that it has become part of the so-called global village. It is a village where competition is rapidly increasing with the click of a mouse at Internet speed. The inescapable reality is that the forces, complexities and interdependencies associated with global economic integration need to be clearly understood by South African business executives and strategically managed to ensure survival in a highly competitive global business context. Globalisation is forcing executives to recognise the need to create value for their clients through the effective utilisation of technology and the redesigning of business systems that take into account the strategic realities associated with globalisation.

The concept "globalisation", from a South African perspective, embodies a sense of both opportunity and threat, both elements that feature prominently in contemporary strategic management theory and practice. While economic integration, access to international markets, and an exchange of technology and information holds significant opportunities for South African business institutions, it also hold the threat of increased competition and exposure to the whims of fluctuating international markets. Adverse developments in international markets 
hold far greater risk for business institutions in developing economies than for the more established institutions in the developed countries of the world. Business institutions in the developed nations tend to have a greater international distribution and delivery capacity and a greater level of experience of international markets and consequently can compete on a far more decisive basis globally.

Two significant conflicting facets of the debate on the effects of globalisation on developing countries centre on issues surrounding opportunities for economic growth and development, and a rather dismal scenario of marginalisation, growing inequalities and increased poverty. The latter issue has engendered rather violent protests at international forums, the latest events in Genoa, being a typical case in point. The increasing disparities between rich and poor, developed and developing nations and similar disparities are generally cited as being a consequence of globalisation. The haves are deemed to be technologically empowered and the have-nots as being technologically disadvantaged. The diametrically opposing positions extend to wealth, access to resources, employment, social justice, quality of life an various related domains.

Having defined the continuum the focus tends to be on the extreme ends thereof and the debate assumes a very emotive polarised connotation of good or bad. The more emotional the debate the greater is the tendency to lose sight of the reality and logic underlying these two opposing positions and the gap between the two extreme ends gets ever greater. The globalisation debate has to a large degree become clouded as a result of the emotion generated by focussing on the extreme ends of the continuum. The emotional connotations associated with the so-called have and have-nots of society tend to engender strong socio-political responses that have a tendency to spill over into the business arena and consequently need to be taken cognisance of in the formulation of strategy.

A key characteristic of the digital global economy is the degree of uncertainty and turbulence that exists in the economic and business marketplace. It frequently translates into a need for reevaluating and redirecting the strategic imperatives that form he foundation of business institutions' day-to-day operations. The digital economy is as much a story about changing business practice to deal with strategic uncertainty and environmental turbulence, as it is about emerging technological innovations. Traditionally land, labour, capital and equipment were the key resources that needed to be effectively managed to ensure optimal wealth creation. Within the industrial era the importance of labour essentially stemmed from the need for physical, manual or the "doing" aspects associated with wealth generation.

Within the digital economy the importance of labour tends to centre on the capitalisation of the collective intellectual or knowledge resources that resides within the organisation. This shift in emphasis has been captured in a host of new business concepts and terminology that have engulfed the management literature, one of the more pertinent being knowledge management. Multimedia, video conferencing, e-mail, data warehousing, and similar ICT infrastructures have given birth to a context that is information rich and one where business practice is increasingly directed at empowering employees at all levels in the organisation to add value to the services and products that are the life blood of the organisation. It is also a context where computer literacy has become an imperative.

People and nations who are technologically marginalized are consequently also deemed to be economically marginalized and consequently consigned to live in poverty and deprivation. Disparities between the availability and use of emerging technology have frequently been cited as a primary cause of exclusion from global markets 
and the ensuing economic advantages that flow there from. It is contended that the world's poorest countries are poor because of their technological isolation. While the technology association with economic development have become well established, the scope of the factors giving rise to the marginalisation of nations and individuals within nations has in instances been extended to incorporate a set of interrelated variables that could be used to explain the gap that exists between nations and individuals within nations in terms of economic well-being. Often the accent has been place on the consequences or symptoms associated with the disparities that exist and in the process the cause giving rise thereto has become blurred with resulting myths and generalisations being fabricated to explain the perceived situation. This has in some instances clouded the issue as to what exactly is meant by the concept "digital divide".

The definition attributed to the concept digital divide within a document of the OECD, directed at generating an understanding of the concept, is quite extensive, namely: "The term "digital divide" refers to the gap between individuals, households, businesses and geographical areas at different socio-economic levels with regard both to their opportunities to access information and communication technologies (ICTs) and their use of the Internet for a variety of activities" (OECD 2001:5).

Seen within the South African context this definition would imply that a significant section of the population are technologically disadvantaged and unlike the North American and European situation ecommerce and e government is constrained by this reality. It also translates into a need for educationists and academics to focus on the technological empowerment of the population, government to set in place an appropriate basic ICT infrastructure to facilitate the move towards the digital economy and business to strategically redesign their business processes and technology systems, to capitalise on the advantages presented by the digital economy and globalisation.

Within the African context South Africa, Egypt, and Botswana are currently probably the best equipped to take advantage of established electronic networks to ensure that they are not excluded from global financial and business markets. It is yet rather disconcerting to note that in the white paper on science and technology it is concluded that South Africa "lacks a national policy to facilitate the country's optimal integration into the global information society". This is described as being a serious defect that needed to be addressed with a sense of urgency, yet to date there appears to be no clearly defined integrating national strategy in this regard. As late as 1999 the Department of Communications, in its discussion paper on electronic commerce policy, notes that while both the government and the business community have begun to take initiatives to expand and upgrade the existing infrastructure, more progress in relation to the direction of policy is required. The economic marginalisation of developing nations, previously alluded to, stems to a large degree from the fact that it is extremely difficult to integrate the economy of developing nations into the global economy if appropriate electronic network infrastructures to support the business processes are not in place. A frequently cited statistic in the literature is that there are more telephone lines in Manhattan and New York City than on the whole African continent. From recent surveys it is estimated that there are about 1.2 million Internet users on the African continent, of which $65 \%$ are in South Africa alone. This stands in stark contrast to the situation that exists in the more developed nations of the world.

A common theme encountered in the contemporary literature is the issue of the importance of intellectual capital within this knowledge era. It has become the primary asset of enterprises such as Microsoft, IBM, and enterprises in the pharmaceutical industry. The use of ICT is seen as a means for developing, accessing and 
sharing of knowledge within the enterprise. The business systems, practices and technology utilisation in the knowledge era are ostensibly directed at establishing profitable relationships with clients.

The conventional rules and practices that applied within the industrial are making way for a new service directed culture. ICT supported business systems, such as customer relationship management (CRM), are increasingly being deployed in an attempt to gain a competitive advantage through service excellence. The name of the game in a highly competitive business context is one of profitably meeting client expectations. This is giving new impetus to a new form of ICT enabled Total Quality Management (TQM), that focuses on the integration of three key ingredients, namely business systems, ICT and human resources. Collectively these elements play a fundamental strategic role in positioning the organisation to meet the challenges presented by globalisation. Access to state of the art ICT alone is no longer a sufficient condition for guaranteeing that business institutions will be ble to survive the turbulence and competitive challenges presented by globalisation, as the human intellectual capital and skills required to integrate the technology with business systems remain a critical consideration in this regard.

As market barriers are eroded through deregulation and political policies of trade and financial liberation, even those institutions that have restricted their business activities to local markets, will no longer be able to avoid the global competitive forces that will increasingly come into play and impact on their activities. This is particularly significant in the case of small medium enterprises that will need to play the competitive game according to a new set of rules that have been briefly eluded to above. The rules are, however, strategically generated as the organisation's strategy defines how the organisation will play the game. Playing the game according to the rules as defined by the major role players in the industry will mean that they have an undeniable competitive advantage, as when the going gets tough they can merely change the rules of the game. All strategic action represents a dialogue between the institution and its environment. Courtney, Kirkland \& Viguerie (1997:68) warn that within turbulent conditions of uncertainty, traditional approaches to strategic planning "can be downright dangerous", as it implies a degree of predictability that is hardly justifiable within turbulent conditions.

Campbell \& Alexander (1997:46) also believe that strategy development is "messier than most textbooks suggest" and view the process essentially as one of discovery and gaining an understanding of value creation within turbulent conditions. This contention is specifically pertinent in view of the renewed emphasis on value chain management, as a strategic issue in integrating ICT and business systems, so as to gain competitive advantage. "No one expects to formulate a detailed long-term plan and follow it mindlessly" according to Luehrman (1998:89), who under conditions $\delta$ highly competitive global markets, suggests that strategy in essence constitutes a portfolio of options that may be pursued. The underlying theme is one of reevaluating traditional strategic management practice in the light of the extensive contextual uncertainty and change emanating of the global village. As noted by Beinhocker (1997:28), in researching strategy at the edge of chaos, "what is needed is a model of a world where innovation, change, and uncertainty are a natural state of things".

The emerging trend within the contemporary strategic management literature is without doubt one of questioning the logic that underpins traditional strategic management theory. Globalisation and the environmental characteristics associated therewith for one appears to challenge the assumptions on which traditional strategic management processes are based. Few of the traditional strategic management models have for instance incorporated ICT strategy as an inherent business critical element. Yet ICT has moved from atraditional administrative support role to one of providing business institutions with the potential to move into and capture far 
greater market share in the global marketplace. It also presents even small business institutions with the potential to form strategic alliances that extend beyond national boundaries, so as to capitalise on the profitable business opportunities that exist in global markets. As previously noted there has also been a move towards knowledge workers with ICT forming the core infrastructure for their involvement in the activities of modern day enterprises. The capacity to transform ICT based intellectual capital into strategic advantage is a critical strategic consideration that can no longer be ignored. It is therefore argued that it has become imperative to ensure that corporate business and ICT strategy are in alignment.

The value of ICT in generating a significant return on investment has frequently been questioned, as ICT infrastructures come with quite a substantial price tag. Many business institutions that in formulating strategy have had to give consideration to e-commerce have been confronted with this dilemma. Conflicting statements as to the return on the investments made and the recent dot.com crash that presented many small enterprises with a major financial headache, are all factors that tend to cloud the issue in terms of the true value that ICT adds to the modern day business institution.

The strategic utilisation of ICT is without doubt a fundamental issue that few business enterprises can afford to not take into consideration. Henderson \& Venkatraman (1999:472) convincingly argue that organisations' inability to realise value from their ICT investments may be traced to a lack of alignment between their business and IT strategies. They view strategic alignment as not constituting an event, but a process of continuous adaptation and change. It is stressed by Luftman, Lewis \& Oldach (1993:205) that "in essence, business and information technology are in alignment when business objectives are enabled, supported and stimulated by information technology strategies".

The alignment of business and ICT strategy has posed the question as to which of the two are the real drivers of corporate strategy. The traditional paradigm of ICT as constituting a support function tends to support the view that the business strategy and the associated processes are first established and consequently the IT strategy and infrastructure is put in place to support the former.

This is essentially in line with traditional conventional thinking. It, however, ignores the alternative perspective of innovative ICT strategy playing a definitive role in redirecting the corporate strategy of the institution concerned. Martin (1995:56) for instance argues that technology is the driver of corporate strategic change and is a key reason for corporate restructuring. Hope \& Hope $(1997: 44,94)$ adopt a slightly different perspective in noting that as new technologies emerge, markets shifts and customer needs change, and to survive enterprises need to look beyond a narrow economic model, to embrace a more responsive strategic model that capitalises on the intellectual capital and commitment of its employees. They therefore link ICT and human resources as key determinant in formulating corporate strategy. The picture that emerges is one of business systems, ICT architecture and human resources infrastructures being brought into alignment by means of an iterative process that takes the strategic determinants of all three into consideration simultaneously. Luftman et al. (1993:203), in terms of their research, conclude that the strategic use of information technology is a fundamental issue for all business institutions, the objective being to design business processes that reflect the interdependence of business strategy and information technology capabilities.

Contemporary enterprises may be conceptualised as a web of interrelated business processes, human resources networks and ICT systems, strategically aligned to realise well researched and defined strategic 
objectives, based on both external and internal environmental considerations that are of strategic importance in ensuring the future growth and survival of the enterprise. To only focus on the business or ICT determinants of corporate strategy, without taking the human resources issues into consideration, could well result in an enterprise either missing or not being able to capitalise on strategic opportunities that may arise from globalisation or new innovative technological developments.

The evolution of innovative technology and new business practices has taken place at an unprecedented rate leaving in its track confusion, uncertainty and a lot of rhetoric that remains largely unsupported by empirical studies. A world of seamless communication that transcends all boundaries giving rise to an information rich society, may sound appealing, but when all the rhetoric is over executives are still left with the task of translating technological possibility into profitable business reality. It is here that the integration of business and technological strategies spell the difference between wishful thinking and opportunistic strategic planning reality.

The realities associated with the digital economy that need to be factored into strategic thinking revolve around two fundamental schools of thought. The first is being the rationalist schoo/ with its underlying principles of scientific management. The second takes a human relations perspective based on the philosophy of organisations as webs of social interaction. The former has tended to focus on business process re-engineering with an accent on the tasks of management, while the latter has accentuated a transformation that is more people orientated. Typical initiatives in the latter category include self directed teams, participative management, knowledge management and total quality management.

In researching management paradigms relating to the digital age both schools of thought seem to prevail, with a possible tendency to accentuate the more human aspects of intellectual capital and knowledge management. The process elements are also, however, ignored by executives - at their peril. One cannot introduce state of the art technology without taking into account the implications on the existing business systems. Value addition along the business value chain is a component of technological and business systems that are integrated into a synergistic strategic entity, while the human factors involved are taken into consideration. Both schools of thought, therefore, are of relevance and need to be taken cognisance of in strategically positioning the organisation to deal with globalisation. It is not a case of the one or the other, but of both schools of thought predominating, both need to be taken into consideration.

Many projects in which state of the art technology has been implemented and business processes have been redesigned to accommodate the new technology, have been difficult to implement as the human elementand the culture of the organisation have not been factored into the strategic equation. These often less tangible elements are in practice the more difficult to manage. Business institutions attempting to identify an explicit model to achieve strategic excellence need to give consideration to the three key elements identified in this paper, namely business systems, ICT and the associated human infrastructures that spell the difference between success and failure in managing the transformation process.

A process management model integrating the three elements is depicted in figure 1. It is based on value chains that extend horizontally across the enterprise and that are directed at profitably meeting client needs and expectations. In the formulation of corporate strategy all three these domains need to be brought into alignment and in all reality this is no easy task. 


\section{BIBLIOGRAPHY}

BEINHOCKER ED. 1997. Strategy at the edge of chaos. McKinsey Quarterly, (1):24-39.

CAMPBELL A \& ALEXANDER M. 1997. What's wrong with strategy? Harvard Business Review, 75(6):42-51, NovemberDecember.

COURTNEY H, KIRKLAND J \& VIGUERIE P. 1997. Strategy under uncertainty. Harvard Business Review, 75(6):67-79, NovemberDecember.

HENDERSON JC \& VENKATRAMAN N. 1999. Strategic alignment: leveraging information technology for transforming organizations. IBM Systems Journal 38(2/3):472-484.

HOPE J \& HOPE T. 1997. Competing in the third wave: the ten key management issues for the information age. Boston : Harvard. LUEHRMAN TA. 1998. Strategy as a portfolio of real options. Harvard Business Review, 76(5):89-99, September-October.

LUFTMAN JN, LEWIS PR \& OLDACH SH. 1993. Transforming the enterprise: the alignment of business and information technology strategies. IBM Systems Journal, 32(1):198-221.

MARTIN J. 1995. The great transition: using the seven disciplines of enterprise engineering to align people, technology, and strategy. New York: Amacom.

MBOWENI TT. 2000. Global competitiveness - is South Africa ready? (Address at the Black Management Forum conference, Sandton Convention Centre, Johannesburg, 13 October.)

OECD. 2001. Understanding the digital divide. Paris : OECD Publications. (A copy of the document can be downloaded from the OECD. [Internet: http://unw.oecd.org] 